\title{
EVALUATING THE EFFECTS OF GENERALISATION APPROACHES AND DEM RESOLUTION ON THE EXTRACTION OF TERRAIN INDICES IN KWAZULU NATAL, SOUTH AFRICA
}

\author{
Jonathan T. Atkinson ${ }^{\mathrm{ab}}$, Andrei B. Rozanov, Willem P De Clercq*c \\ ${ }^{\text {a }}$ Kwazulu Natal Department of Agriculture and Rural Development, Cedara, 3245, KZN \\ ${ }^{\mathrm{b}}$ Stellenbosch Department of Soil Science, Matieland, Stellenbosch \\ ${ }^{\mathrm{c} S}$ Stellenbosch Water Research Institute, Matieland, Stellenbosch, \\ *Corresponding authors email: wpdc@sun.ac.za
}

DOI: http://dx.doi.org/10.4314/sajg.v6i2.9

\begin{abstract}
Digital elevation model (DEM) data are elemental in deriving primary topographic attributes which serve as input variables to a variety of hydrologic and geomorphologic studies. There is however still varied consensus on the effect of DEM source and resolution on the application of these topographic attributes to landscape characterisation. While elevation data for South Africa are available from several major sources and resolutions: Shuttle Radar Topographic Mission (SRTM), Earth ENV and Stellenbosch University DEM (SUDEM). Limited research has been conducted in a local context comparing the extraction of terrain attributes to high resolution Digital Terrain Data (DTM) such as LiDAR (Light Detection and Ranging) that are becoming increasing available. However, the utility of LiDAR to topographic analyses presents its own challenges in terms of operational-relevant resolution, processing demands and limited spatial coverage. There is a need to quantify the impact that generalisation approaches have on simplifying detailed DEMs and to compare the accuracy and reliability of results between high resolution and coarse resolution data on the extraction of localized topographic variables. In this regional study, we analyse the accuracy on selected local terrain attributes: elevation, slope and topographic wetness index derived from DEMs from varying sources, at different spatial resolutions and using three generalisation algorithms, namely: mean cell aggregation, nearest neighbour and hydrological corrected topo-toraster. We show that topographic variable extraction is highly dependent on DEM source and generalisation approach and while higher resolution DEMs may represent the "true" surface more accurately, they do not necessarily offer the best results for all extracted variables. Our results highlight the caveats of selecting DEMs not "fit-for-purpose" for topographic analysis and offer a simple yet effective solution for reconciling the selection of DEMs based on neighbourhood size resolution prior to terrain analyses and topographic feature characterization.
\end{abstract}




\section{Introduction}

Digital Elevation Models (DEMs) provide a convenient and representative interpretation of the Earth's surface and are generally considered to be the de-facto dataset(s) for a variety of terrain and spatial analyses. The topographic analyses of pedo-geomorphological processes using DEMs are well established and are central to the catena concept for soil formation (Hook and Burke, 2000). This is because the development and variation of soil properties is strongly influenced by the way water and soil materials interact with the land surface and often co-evolve with the local topography. Using scale-specific DEMs to derive key topographic indices specifically related to soil formation is therefore essential for spatially representing soil-landscape phenomena, the basis for disciplines such as digital soil mapping (DSM). In recent years however there has been significant interest in improving the scale and accuracy at which soil-landscape relationships are modelled and represented, from a local through to national scale (Maynard and Johnson, 2014). Concomitantly, high on the research agenda is the need for developing novel ways of exploring the complexity associated with deterministic characterisation and modelling approaches of topographical landforms (Bishop, James, Shroder and Walsh, 2012) and relating various soil properties to readily available spatial data such as digital elevation data (Mashimbye, De Clercq and Van Niekerk, 2014).

The use of geographic information system (GIS) based terrain analyses to objectively identify and delineate soil-landscape units therefore requires a solid understanding of the correct application of spatial scale and grid resolution for feature selection and information generalisation. In fact Cavazzi, Corstanje, Mayr, Hannam and Fealy (2013) point out that due to the complexity of the scale-resolution dichotomy, determining this optimal relationship is often dependent on the context of the study and remains in large an unresolved issue with only a few empirical guidelines available. Cavazzi et al., (2013) further point out that the main challenges with DEM pixel resolution are that firstly at finer resolutions the terrain variables contain too much unnecessary detail or "noise" that may lead to poorer modelled accuracies. Secondly at coarser resolutions terrain variables may show too much generalisation or "smoothing" and not adequately represent terrain attributes or the land surface, ultimately compromising the predictive capacity of soil-landscape models. A study conducted by Zhang, Chang and Wu (2008) concluded that DEMs with different resolutions and accuracies generated varied topographic and hydrological surface matrices which in turn affected their soil erosion models. The study conducted by (Cavazzi et al., 2013) therefore provides necessary insight into the behaviour of DEMs to various scale and neighbourhood algorithms. Their study showed that coarser resolution DEMs (140m) performed better in flat homogenous areas, regardless of window search sizes. Whereas in areas that were morphologically more varied with abrupt changes in topography, finer resolution DEMs $(30 \mathrm{~m})$ with smaller windows outperformed coarser DEMs and larger window search radii.

Regarding the matter of platform selection and DEM origins, the ability of sensors such as LiDAR (Light Detection and Ranging), or interferometry, to readily provide very high resolution bare surface models has allowed researchers to investigate whether terrain attributes derived at finer resolutions are more correlated to pedo-geomorphic properties. However current research hypotheses on the contribution of LiDAR to DSM seems varied. In particular, Hodgson et al. (2005) were able to show that specific terrain matrices derived from LiDAR showed higher accuracies when compared to data 
derived from synthetic aperture radar (SAR). However, Thompson, Bell and Butler (2001) contend that higher resolution DEMs may not be necessary for producing functional soil-landscape models. In contrast, other sources of readily available medium to coarse resolution near-global DEMs such as the Shuttle Radar Topography Mission (SRTM), the Advanced Space borne Thermal Emission and Reflection Radiometer (ASTER), the global EarthEnv-DEM90 (Robinson, Regetz and Guralnick, 2014) and more region specific Stellenbosch University Digital Elevation Model (SUDEM) need further assessment to compare the quality of terrain derived products as input covariates for DSM in South Africa. This regional study therefore builds on the scientific incentive to further assess the utility of applying DEMs from varying sources, at different spatial resolutions and using various generalisation and algorithms for optimal geomorphological analysis. The aim would be to demonstrate the importance of utilising DEM surfaces that are "fit-for-purpose" for describing the scale-dependent pedo-geomorphic inputs relevant to soil-landscape modelling. More specifically, the study had two primary objectives. First, to compare the variation in selected topographic indices derived from high a resolution base DTM (1m LiDAR data) using three generalisation approaches across different resampled surface resolutions. Second, to compare these LiDAR derived products with those products derived from the most common and widely accepted regional and near global DEM surfaces to compare the variation in topographic representation within an area.

\section{Materials and Methods \\ 2.1 Study site}

The study was conducted in the commercial forestry plantation known as Braemar $\left(30^{\circ} 23^{\prime}\right.$ 18.53 ' 'E, $30^{\circ} 22^{\prime} 35.06^{\prime}$ 'S) situated in the vicinity between Kenterton and Braemar, south of the town of Durban in the Kwazulu-Natal Province of South Africa (Figure 1). The mono-cultured Eucalyptus dominated plantation is owned and managed by Sappi Southern Africa's Forestry Division and has an extent of approximately 5200ha. The study site was selected based on the fact that it was one of the first inland/coastal forestry plantations to have had LiDAR data acquired that could be combined with the vast gridded field surveyed soil data that exists for a large proportion of Sappi's plantations, Braemar included. The region generally has a rolling or undulating topography dominated by moderate to steep slopes (> 12\%). River catchments dominate the landscape creating a terrain of closed hills, high relief, deep valleys and hilltop plains with moderate relief. The altitude range for the region varies from sea level to $950 \mathrm{~m}$ while in the study site, the altitude range is from $200 \mathrm{~m}$ to $820 \mathrm{~m}$. Pedologically, shallow, weakly weathered soils as well as yellow-brown block clay subsoils and yellow mottled waterlogged subsoil dominate across the study site (SASRI, 1999). 


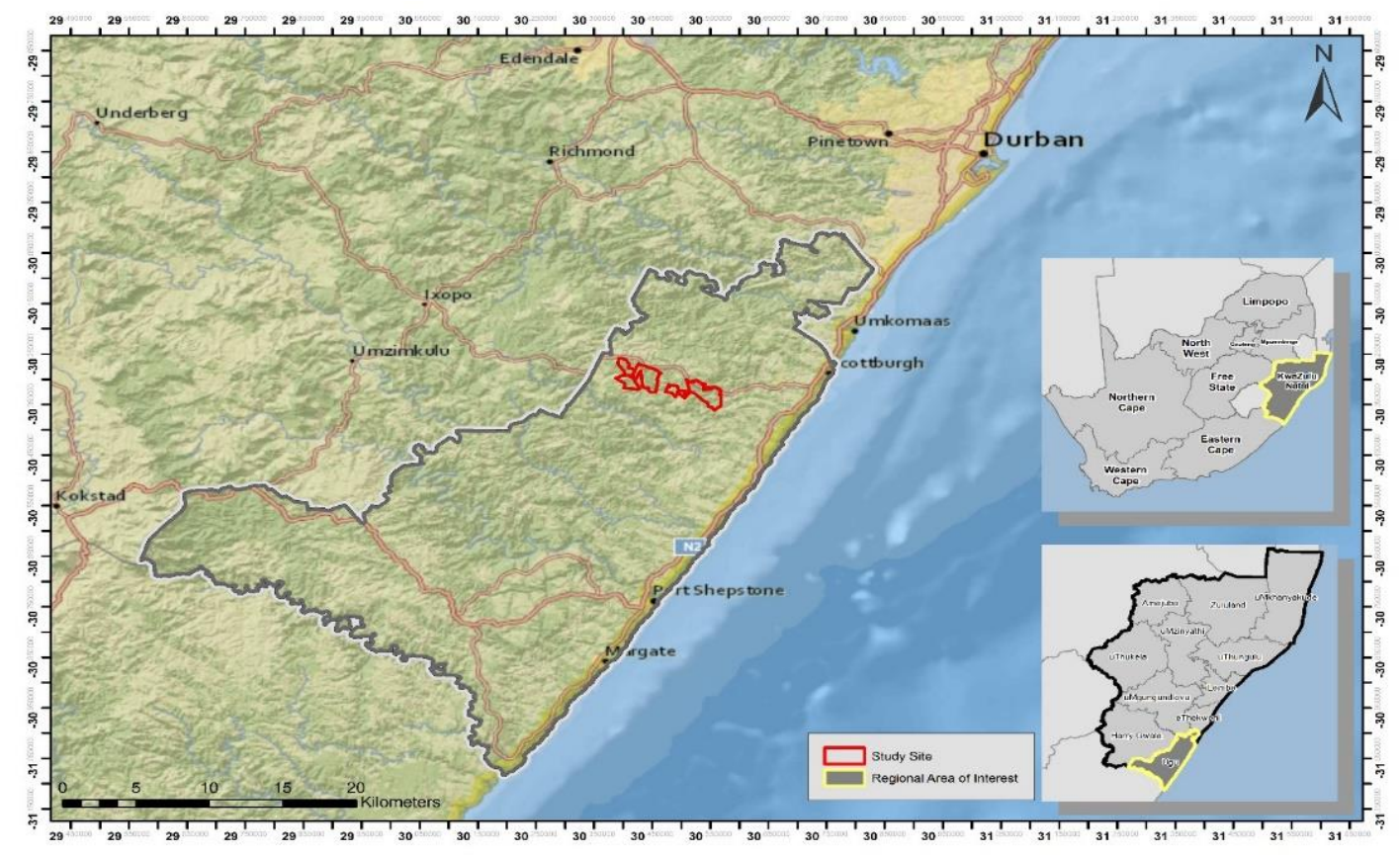

Figure 1: Location of study site near Braemar.

\subsection{DEM Datasets}

Airborne-based LiDAR for the study site was acquired using the Leica ALS50-2 multi-phase laser scanner with a CUS6 "uIRS" inertial measurement unit and XP embedded data logger on the 24 and 25 of January, 2015 by Land Resources International Pty (Ltd). The LiDAR imagery was collected at an average flight height of $800 \mathrm{~m}$ AGL with a swath width of $324 \mathrm{~m}$ and a minimum flight line overlap of $50 \%$ and $25^{\circ}$ field of view. Point cloud densities ranged from 4.3 pulse $\mathrm{m}^{-2}$ to 13 pulses $\mathrm{m}^{-}$ ${ }^{2}$ with an overall average density of 7.4 pulses $\mathrm{m}^{-2}$. All post processing of the acquired data was done by the vendor using Terrapos (http://www.terrapos.no) to process the raw LiDAR data and final trajectories to projected format and to correct for positional accuracy. The TerraScan ${ }^{\circledR}$ suite of tools (https://www.terrasolid.com) was then employed to process, classify and clean the point cloud data to yield the final ground and non-ground LiDAR products. Extensive QA/QC was conducted on the LiDAR data to ensure that correct geoidal model (SAGeoid2010) was applied as a height correction from ellipsoidal height mean sea level. Furthermore, the survey was conducted using a real time fix to the TrigNET and VRS broadcast system with horizontal calibration using the SCOT (Scottburgh) TrigNET station and the Hartebeesthoek 94 Datum. The final $1 \mathrm{~m}$ resolution LiDAR DTM product was exceptionally good at representing the terrain surface delivering overall residuals that showed a maximum height error $0.17 \mathrm{~m}$ with an average magnitude of $0.06 \mathrm{~m}$ and a RMSE of $0.08 \mathrm{~m}$ across all data collected. The original LiDAR DEM, and associated LiDAR derived (LD) products were compared to other freely available broad-scale satellite derived DEMs in extracting selected topographic matrices. These medium-resolution elevation products, hereafter referred to as nonLiDAR derived (NLD) products, included: the global 1arc-second (30m) void-filled Shuttle Radar Topographic Mission (SRTM) (http://lpdaac.usgs.gov) as well as the 3 arc-second (90m) SRTM ((http://www.cgiar.org) the 5m Stellenbosch DEM (SUDEM) (Van Niekerk, 2011, 2014) and a relatively new global DEM known as the EARTHEnv-90 comprised of the 1 arc-second Advanced 
Spaceborne Thermal Emission and Reflection Radiometer Global DEM2 (ASTER GDEM2) (http://gdem.aster.ersdc.or.jp), 3 arc-second CGIR CSI SRTM v4.1 and 3 arc-second GLSDEM (Robinson et al., 2014). Nelson, Reuter and Gessler (2009) have compared DEM data across various data sources and have provided a very useful comparison of the major features of each of these DEM option. Table 1 has been adapted to highlight only the key components of the data sets used in this study. For detailed descriptions and applications of the sensors used in this study the reader is referred the studies conducted by (Farr and Kobrick 2001; Rodriguez, Morris and Belz, 2005; Farr et al. 2007; Prasannakumar, Shiny, Geetha and Vijith 2011; Robinson et al. 2014; Gesch, Oimoen, Zhang, Danielson, Meyer, 2011; Van Niekerk, 2012).

Table 1: Key properties of datasets used in study (Modified from Nelson, et al., 2009 in Wilson, 2012)

\begin{tabular}{|c|c|c|c|c|c|}
\hline Source & Resolution (m) & Accuracy & Footprint (Km2) & Post-Processing & Eevation/Surface \\
\hline LiDAR & 1 to 3 & $\begin{array}{l}0.15 \text { - } 1 \mathrm{~m} \text { vertical, } \\
1 \mathrm{~m} \text { horizontal }\end{array}$ & User defined & High & Surface \\
\hline SUDEM & 2 to 5 & $2.1-4.6 \mathrm{~m}$ vertical & $\begin{array}{l}\text { Provincial/ User } \\
\text { defined }\end{array}$ & Low & Surface/ Elevation \\
\hline SRTM, Band C & 90,30 & $\begin{array}{l}16 \mathrm{~m} \text { vertical, } \\
20 \mathrm{~m} \text { horizontal }\end{array}$ & $\begin{array}{l}\text { Near global, } 60^{\circ} \\
\mathrm{N} \text { to } 58^{\circ} \mathrm{S}\end{array}$ & Potentially high & Surface/ Elevation \\
\hline SRTM, Band X & 30 & $\begin{array}{l}16 \mathrm{~m} \text { vertical, } \\
6 \mathrm{~m} \text { horizontal }\end{array}$ & $\begin{array}{l}\text { Similar to C, but } \\
\text { only every } \\
\text { second path is } \\
\text { available }\end{array}$ & Potentially high & Surface/ Elevation \\
\hline ASTER & 30 & $\begin{array}{l}\text { 7-50m vertical, } \\
7-50 \mathrm{~m} \text { horizontal }\end{array}$ & 3600 & Medium & Surface/ Elevation \\
\hline EarthEnv & 90 & $\begin{array}{l}\text { 7-50m vertical, } \\
6-50 \mathrm{~m} \text { horizontal }\end{array}$ & Near global & Medium & Surface/Elevation \\
\hline
\end{tabular}

\subsection{DEM Surface Generalisation}

The first objective of the study was to evaluate the effect of DEM resolution and spatial extents on the extraction of selected terrain attributes using different generalisation approaches. This was done using a similar approach proposed by (Gillin, Bailey, McGuire and Prisley, 2015) and (Maynard and Johnson, 2014). We compared the values of terrain matrices derived from $1 \mathrm{~m}$ resolution using the original LiDAR DEM resampled to six lower resolution LiDAR derived DEMS, (5, 10, 20, 30, 60 and $90 \mathrm{~m}$ grid resolution intervals). Three interpolation methods namely, mean aggregation (MA), nearest neighbour resampling (NNR) and a hydrological conditioned approach known as topo-toraster interpolation (HCD) were evaluated to determine which generalisation and resolution combination best represented the $1 \mathrm{~m}$ (LiDAR true ground measurement) terrain parameters. This resulted in 22 unique resolution-generalisation combinations with 66 topographic iterations. All datasets were processed using the Earth Science Research Institutes ArcGIS ${ }^{\circledR}$ (ArcMap ${ }^{\mathrm{TM}}$, version 10.4) (ESRI, 2015) Spatial Analyst's generalisation toolbox. A similar approach has been adopted in this work as was taken in Wise (2000) which is to conduct the analyses using interpolation methods that are readily available to non-specialists in commercial GIS software packages. While the generalisation methods used in this study may not be the most superior for DEM interpolation, with more classical interpolators such as kriging, co-kriging, inverse distance weighting and radial basis function offering viable alternatives to surface generalisation (Chen and Yue 2010; Zhou and Chen, 2011) our study opted to investigate the most common methods (Podobnikar, 2005) typically used to produce DEM surfaces from a wide variety of data sources. However their ease of use and out-thebox application will most likely appeal to non-specialists for DEM creation from their own data. 
With the second goal of the study, the authors endeavoured to investigate how the use of satellite derived DEMs, such as the SRTM, ASTER and EartEnv90 datasets, influence the representation of extracted topographic variables within the study site at the same resolution as the LiDAR products i.e. the LiDAR 30m and 90m products would be compared to the SRTM 1 arc-second dataset, 3 arcsecond and EarthEnv 90 datasets respectively. These open source DEM products were corrected by the agencies responsible for their distribution to an acceptable level of application for this study and therefore no additional post-processing was performed on any of the third-party DEM surfaces.

\section{$2.4 \quad$ Terrain Analysis}

All digital terrain and local morphometric data were analysed and processed using $\operatorname{ArcGIS}^{\circledR}$ as well as the System for Automated Geoscientific Analyses (SAGA) (Conrad et. al., 2015) software since both software programs provide all the necessary tools for DEM and terrain property analysis, to derive the following terrain indices for each of the 22 DEM datasets: elevation, slope and topographic wetness index $(T W I)$. These topographic attributes were selected as they are thought to be the most indicative of the predominant morphological, ecological and hydrological drivers within the soil-landscape environment and considered as potential explanatory variables for predicting a range of soil-landscape related properties (Florinsky, 2011). A number of studies address in detail the description and importance of these terrain attributes mentioned with regards to soil-landscape and DSM and the reader is referred to selected key studies for further review, namely (Gillin et al., 2015; MacMilland and Shary, 2009; Florinsky, 2011; Maynard and Johnson, 2014; Thompson et al., 2001 and Tesfa, Tarboton, Chandler, and McNamara 2009). A brief description of each investigated terrain variable will be provided for the purposes of this study (Table 2).

Table 2: summary description of terrain variables evaluated in this study

\begin{tabular}{lcll}
\hline \multicolumn{1}{c}{ Terrain Attribute } & Unit & Description & Reference \\
\hline Elevation & {$[\mathrm{m}]$} & Elevation above sea level & Tesfa et al., 2009 \\
Slope & {$[\%]$} & Angle of inclination of the surface between the tangent and horizontal plans. & Cavazzi, 2013 \\
& & $\begin{array}{l}\text { A steady state wetness index as a function of slope and upstream contributing } \\
\text { area per unit width orthogonal to the flow of direction. High values indicate }\end{array}$ & Gessler et al., \\
$\begin{array}{l}\text { Topographic Wetness } \\
\text { large, gentle upslope areas with high water availability while small index values } \\
\text { indicate steep, small upslope areas with low water availability. }\end{array}$ & 1995
\end{tabular}

The Forest Industry Soils Database (FSD) Co-operative gridded surveyed data (Erasmus, 1998) collected for the study site provided the sampling locations for the terrain data extraction with a total of 813 points across the study analysed. The FSD data is a compilation of industry standard soil surveyed data across selected forested areas in South Africa with detailed modal profile data collected at each site. The modal soil parameters, which include inter alia, soil depth; wetness; texture; structure, colour, available soil water and organic carbon, were not considered for this study but may however provide further insight in evaluating potential soil-landscape trends in future research studies. 


\subsection{Statistical Analysis}

Four assessment approaches were used to evaluate the accuracy and quantify the level of agreement between the various scale-dependent DEM generalisation outputs. This included the evaluation of several popular statistical measures: the Mean Absolute Deviation (MAD), Standard Error of Mean (SEM), and finally the Nash-Sutcliffe efficiency coefficient. For this study the MAD was opted for in favour of the RMSE as a measure of representing model prediction error and evaluating their performance (Aguilar, Aguilar, Agüera, Aguilar and Carvajal, 2005; Guo, Li, Yu, and Alvarez, 2010) which can be either negative or positive and thus can report systematic under- or over estimation of DEM elevation error (bias) Desmet, 1997; Tate and Fisher 2006; and Thomas, Joseph, Thrivikramji and Arunkumar, 2014). In all assessments the original 1m LiDAR DEM were considered to represent the 'actual' geomorphological surface from which the LD as well as NLD surface products, were benchmarked against. Table 3 presents the descriptive statistics resulting from the topographic analysis and surface generalisation across the various sensor platforms and spatial resolutions across the entire site. The SEM was used to represent how well the predicted DEM values $(L D \& N L D)$ approximate the actual DEM (1m LiDAR) values with smaller values of the SEM showing higher agreement with the actual DEM values. Likewise, the inter-correlation coefficient (ICC) is a measure of the homogeneity of observations within the DEM classes relative to the variability of such observations between the DEM classes (Hays, 1988). Finally, the Nash-Sutcliffe efficiency coefficient, also known as the efficiency criterion $(E)$, was used as a measure of statistical association, indicating the percentage of the observed variance that is explained by the model (Nash and Sutcliffe, 1970). Values of $E$ range from 1.0 (perfect fit) to - $\infty$ with values below zero indicating that the mean of the observed data (actual) would have been a better predictor than the model (predicted) (Krause and Boyle, 2005).

Table 3: Statistical summary of study site extracted topographic matrices for each generalisation method and pixel resolution/ filter combinations including results for non-LiDAR sensors

\begin{tabular}{|c|c|c|c|c|c|c|c|c|c|c|c|c|c|c|c|c|c|c|c|c|c|c|}
\hline \multicolumn{11}{|c|}{ DEM } & \multicolumn{6}{|c|}{ SLOPE } & \multicolumn{6}{|c|}{ TWI } \\
\hline Data Source & Resolution & Mean & Min & $\operatorname{Max}$ & $S D$ & Corr & $M A D$ & SEM & $I C C$ & NSEG & Mean & Min & $\operatorname{Max}$ & $S D$ & Corr & $M A D$ & Mean & Min & Max & $S D$ & Corr & $M A D$ \\
\hline Lidar $1 \mathrm{~m}$ & & 576.00 & 237.00 & 784.00 & 121.00 & & & & & & 26.00 & 1.00 & 136.00 & 17.00 & & & 4.82 & 0.26 & 16.11 & 1.71 & & \\
\hline \multicolumn{23}{|l|}{ Aggregated } \\
\hline & 5 & 576.08 & 237.75 & 784.49 & 120.91 & 0.99 & 0.30 & 4.24 & 1.00 & 1.00 & 24.37 & 1.46 & 101.37 & 13.68 & 0.83 & 5.79 & 5.41 & 2.31 & 17.13 & 1.39 & 0.48 & 1.03 \\
\hline & 10 & 576.09 & 238.63 & 784.68 & 120.93 & 0.99 & 0.60 & 4.24 & 1.00 & 1.00 & 23.99 & 1.22 & 73.37 & 12.89 & 0.78 & 6.43 & 5.54 & 3.18 & 16.56 & 1.41 & 0.32 & 1.16 \\
\hline & 20 & 575.97 & 238.75 & 785.26 & 120.97 & 0.99 & 1.20 & 4.24 & 1.00 & 1.00 & 23.28 & 1.60 & 59.08 & 12.05 & 0.74 & 7.25 & 5.75 & 3.72 & 15.50 & 1.46 & 0.32 & 1.31 \\
\hline & 30 & 576.08 & 241.53 & 784.85 & 120.92 & 0.99 & 1.80 & 4.24 & 0.99 & 1.00 & 22.41 & 1.70 & 56.44 & 11.33 & 0.70 & 8.03 & 5.88 & 3.92 & 15.17 & 1.38 & 0.26 & 1.42 \\
\hline & 60 & 575.77 & 240.37 & 783.57 & 120.91 & 0.99 & 3.30 & 4.24 & 0.99 & 1.00 & 19.49 & 1.11 & 51.82 & 9.26 & 0.58 & 10.28 & 6.41 & 4.59 & 15.07 & 1.48 & 0.24 & 1.84 \\
\hline & 90 & 575.49 & 245.69 & 785.59 & 120.85 & 0.99 & 5.10 & 4.24 & 0.99 & 1.00 & 16.75 & 0.47 & 43.89 & 7.80 & 0.46 & 12.32 & 6.84 & 0.00 & 15.22 & 1.52 & 0.13 & 2.26 \\
\hline \multicolumn{23}{|l|}{ Hydro } \\
\hline & 5 & 576.08 & 239.06 & 784.51 & 120.93 & 0.99 & 0.40 & 4.24 & 1.00 & 1.00 & 24.08 & 0.04 & 66.77 & 13.02 & 0.77 & 6.65 & 5.44 & 2.98 & 15.75 & 1.33 & 0.34 & 1.13 \\
\hline & 10 & 575.99 & 239.55 & 784.36 & 120.85 & 0.99 & 1.00 & 4.24 & 1.00 & 1.00 & 23.21 & 0.61 & 58.09 & 12.57 & 0.71 & 7.44 & 5.64 & 3.47 & 14.89 & 1.48 & 0.36 & 1.24 \\
\hline & 20 & 575.56 & 239.97 & 784.30 & 120.72 & 0.99 & 2.70 & 4.23 & 1.00 & 1.00 & 20.25 & 0.14 & 53.38 & 11.57 & 0.58 & 10.10 & 6.06 & 3.89 & 16.33 & 1.55 & 0.21 & 1.59 \\
\hline & 30 & 574.54 & 238.87 & 781.37 & 120.66 & 0.99 & 5.00 & 4.23 & 0.99 & 1.00 & 16.63 & 0.00 & 48.69 & 11.13 & 0.42 & 13.12 & 7.83 & -1.51 & 18.37 & 3.85 & 0.00 & 4.22 \\
\hline & 60 & 571.76 & 241.01 & 782.42 & 120.27 & 0.99 & 13.00 & 4.22 & 0.99 & 0.98 & 9.23 & 0.00 & 34.57 & 8.85 & 0.19 & 18.79 & 8.41 & 4.66 & 19.60 & 2.34 & 0.04 & 3.76 \\
\hline & 90 & 566.91 & 263.26 & 726.48 & 114.86 & 0.99 & 24.00 & 4.03 & 0.98 & 0.94 & 5.14 & 0.00 & 27.21 & 6.37 & 0.12 & 21.70 & 9.86 & 6.01 & 18.15 & 2.22 & 0.07 & 5.11 \\
\hline \multicolumn{23}{|l|}{ Resample } \\
\hline & 5 & 576.10 & 237.12 & 784.18 & 120.94 & 0.99 & 0.30 & 4.24 & 1.00 & 1.00 & 24.40 & 1.12 & 93.57 & 13.74 & 0.83 & 5.65 & 5.40 & 1.44 & 17.88 & 1.51 & 0.54 & 1.00 \\
\hline & 10 & 576.08 & 237.85 & 783.81 & 120.90 & 0.99 & 0.60 & 4.24 & 1.00 & 1.00 & 23.99 & 1.50 & 80.34 & 13.08 & 0.77 & 6.51 & 5.54 & 3.37 & 17.56 & 1.48 & 0.37 & 1.15 \\
\hline & 20 & 576.01 & 238.01 & 783.63 & 120.91 & 0.99 & 1.30 & 4.24 & 1.00 & 1.00 & 9.17 & 0.70 & 22.81 & 4.21 & 0.52 & 17.33 & 5.75 & 3.68 & 15.49 & 1.47 & 0.35 & 1.29 \\
\hline & 30 & 576.19 & 241.36 & 785.10 & 120.87 & 0.99 & 1.90 & 4.24 & 0.99 & 1.00 & 22.77 & 1.01 & 59.19 & 11.63 & 0.70 & 7.89 & 5.84 & 3.66 & 15.32 & 1.39 & 0.28 & 1.40 \\
\hline & 60 & 576.01 & 237.70 & 783.73 & 3120.84 & 0.99 & 3.50 & 4.24 & & 1.00 & 20.41 & 1.11 & 53.36 & 9.94 & 0.59 & 10.01 & 6.36 & 4.40 & 15.29 & 1.52 & 0.25 & 1.81 \\
\hline & 90 & 575.81 & 242.31 & 785.92 & 2120.76 & 0.99 & 5.30 & 4.24 & 0.91 & 1.00 & 17.88 & 0.81 & 49.62 & 8.55 & 0.45 & 11.96 & 6.75 & 0.00 & 15.47 & 1.66 & 0.13 & 2.23 \\
\hline SUDEM & 5 & 583.93 & 248.21 & 788.72 & 2119.88 & 0.99 & 8.00 & 4.20 & 0.99 & 0.99 & 18.61 & 1.08 & 64.22 & 10.00 & 0.52 & 11.08 & 5.98 & 2.90 & 17.89 & 1.41 & 0.22 & 1.57 \\
\hline SRTM & 30 & 588.14 & 253.00 & 794.00 & 118.63 & 0.99 & 12.00 & 4.16 & 0.99 & 0.98 & 20.67 & 0.00 & 62.15 & 11.04 & 0.45 & 11.40 & 6.14 & 3.98 & 16.95 & 1.62 & 0.13 & 1.77 \\
\hline SRTM & 90 & 586.93 & 260.00 & 793.00 & 118.28 & 0.99 & 13.00 & 4.15 & 0.89 & 0.98 & 16.07 & 0.58 & 48.98 & 8.45 & 0.30 & 13.61 & 6.99 & 4.93 & 15.69 & 1.71 & 0.06 & 2.42 \\
\hline EARTHENV & 90 & 586.13 & 262.00 & 789.00 & 118.41 & 0.99 & 12.00 & 4.15 & 0.90 & 0.98 & 14.60 & 0.58 & 52.17 & 7.73 & 0.25 & 14.60 & 7.16 & 5.06 & 16.84 & 1.62 & 0.05 & 2.58 \\
\hline
\end{tabular}

$S D=S t a n d a r d$ Deviation, Corr=Correlation, MAD=Mean Absolute Deviation, SEM=Standard Error of Mean, ICC=Inter Correlation

Coefficient, $H D=$ Horizontal Deviation, NSEG= Nash-Sutcliffe Efficiency Criteria 


\section{Results and Discussion}

\subsection{Comparison of Digital Elevation Products}

The correlation between the resampled (predicted) LiDAR elevation surfaces as well as the nonLiDAR DEMS to the original LiDAR (actual) surface produced a goodness-of-fit close to 1, with correlation values ranging between 0.992 for the least best performing DEM and 0.999 for the best modelled DEM surfaces (Table 3). The correlation coefficients however merely show the robustness of the relationship between the actual and predicted surface suggesting that all of the predicted surfaces vary in the same direction, at the same point in the feature space (study site) and similar magnitude as the actual surface across the study site $(n=813)$. The correlation coefficient relationships reported in this study are similar to those reported by (Shafique, Van der Meijde, Kerle and Van der Meer, 2011) comparing similar DEM products across the same resampled pixel resolutions.

The Nash-Sutcliffe Efficiency values for all the LD and NLD DEM surfaces ranged from 0.94 to 0.99 indicating that all of the simulated DEM surfaces are suitable predictors for the observed surface through all 22 DEM surface products. As Grohmann and Sawakuchi, (2013) suggest, this may seem somewhat counterintuitive, as one would expect the difference in elevation to vary significantly with varying cell sizes and sensor platform. However, Gonga-Saholiariliva, Gunnell, Petit and Mering, (2011) point out, these simple global metrics may conceal substantial local variability between data sets; and alternative methods may be necessary to provide further insight into the variability between surface products. They offer an explanation for this observed trend by suggesting that even though error may be present in the various DEMs, including outliers, neither data scatter in the linear regression models nor variance in the vertical accuracy constitute sufficient criteria to achieve a full definition of DEM error because the error is expressed globally i.e. across the entire study site. Importantly, the findings are in agreement with studies conducted by (Gonga-Saholiariliva et al., 2011; Barber and Shortridge, 2005; Shi et al., 2012).

While the variability between the LD DEM surfaces at a global scale were generally uniform, there were still minor trends evident between the different generalisation approaches and pixel resolutions. A comparative analysis of the Mean, Median, Min and Max elevation values for the predicted surfaces showed minor differences from the true $1 \mathrm{~m}$ LiDAR surface. As anticipated, the general trend exhibited a decrease, or underestimation, of the LD elevation surfaces as the resolution decreased from $60 \mathrm{~m}$ to $90 \mathrm{~m}$ when applying both the $M A$ and $N N R$ approaches. Of the three generalisation approaches, the $H C D$ performed the least consistent in predicting the true surface with surface error predictions manifesting from as low as $10 \mathrm{~m}$ and ranging from $0.4 \mathrm{~m}$ to $24 \mathrm{~m}$ between surface models. Figure 2 provides a further snapshot view of the variation in elevation surface between the generalisation approaches and pixel resolutions between the original LiDAR and LD and NLD surfaces. Visually it is clearly evident that the 30,60 and 90m HCD surface generates a far less accurate representation of the true surface model. It should be cautioned however that this variation is predominantly due to the fact that the $H C D$ model typically alters the terrain morphology to account for hydrological surface flow. The general decrease in pixel resolution between all the products clearly shows a loss of surface representation, regardless of generalisation approach used. The coarse resolution products do not appear to capture the necessary surface or topographic detail for site 
specific terrain analyses. The 90m products may therefore offer limited functionality for DSM given that certain geomorphology process that drive pedological formations are not adequately detected at coarser resolutions. More importantly, with the exception of the $H C D$ approach at selected resolutions, all three approaches were generally able to produce DEM surfaces with lower MAD from the original LD surface than the NLD surfaces when compared at the same resolution.

Notwithstanding, the MAD error for the NLD surfaces were within acceptable levels of magnitude to be applicable to landscape-level assessments with vertical errors ranging between 8 to $12 \mathrm{~m}$. Interestingly though, unlike the generalized LD DEMs that consistently under predicted the true surface model the NLD DEMS were more prone to over predict the true $1 \mathrm{~m}$ surface model. These findings are in line with similar studies which showed that SRTM and ASTER derived surface products tend to over predict surface elevation values. It has been suggested that this phenomena may be related to the different data acquisition and/or processing methods applied to both the SRTM and ASTER datasets (Jarihani, Callow, McVicar, Van Niel and Larsen, 2015). Another possible explanation for the over-prediction of DEM surface with the NLD is that unlike the LD products which represent a true surface model, the NLD surface products detect reflective surfaces and represent the height of imaged surfaces and not the bare surface height. Consequently, should an area be dominated by obtrusive surface features, as is the case with the study site being dominated by a variety of mixedage commercial tree species, the above ground features are likely to result in a positive elevation bias (Gesch et al., 2011). With that being said, the vertical error related to the SRTM DEM surfaces reported in this study are still well within the performance requirements for absolute and relative vertical error of 16 and $10 \mathrm{~m}$ respectively and typically associated with the SRTM datasets (Rodriguez et al., 2005).

The preliminary observation is that at the macro-landscape scale, the choice of DEM interpolation approach, DEM data source and even pixel resolution, does not produce significant surface elevation variation from the true surface model. In fact, similar to (Gonga-Saholiariliva et al., 2011) elevation values for the NLD surfaces are comparatively similar to the reference LiDAR surface and thus perform almost as well as the most accurate reference grids despite their comparatively lower initial resolution.

This is promising since issues of DEM resolution, precision, and sensor-type are increasingly being pushed to the limit of their application for soil-landscape level models especially where detailed topographic field surveys are not feasible (Thompson et al., 2001). These results therefore further highlight the importance of sensor selection and resolution importance for certain soil-landscape studies given the acquisition costs, processing demands and limited footprint of LiDAR products versus the accessibility of products such as SRTM, EarthEnv DEMs and the locally derived high resolution SUDEM. 


\subsection{Analyses of Derived Terrain Parameters}

\subsubsection{Slope}

The predicted slope values show higher levels of variability across generalisation approach than the DEM predictions across spatial resolutions. (Table 3). Moreover, there appears to be an inverse trend of slope variability and pixel resolution across all generalisation approaches including the nonLiDAR platforms (Figure 2b). Firstly, with all three generalisation approaches the $S D$ is lower as the pixel resolution decreases with the $90 \mathrm{~m}$ products consistently showing the lowest variability. It could be argued that this is to be expected given that the coarser resolution products represent a more generalized surface with less surface detail and therefore less variability.

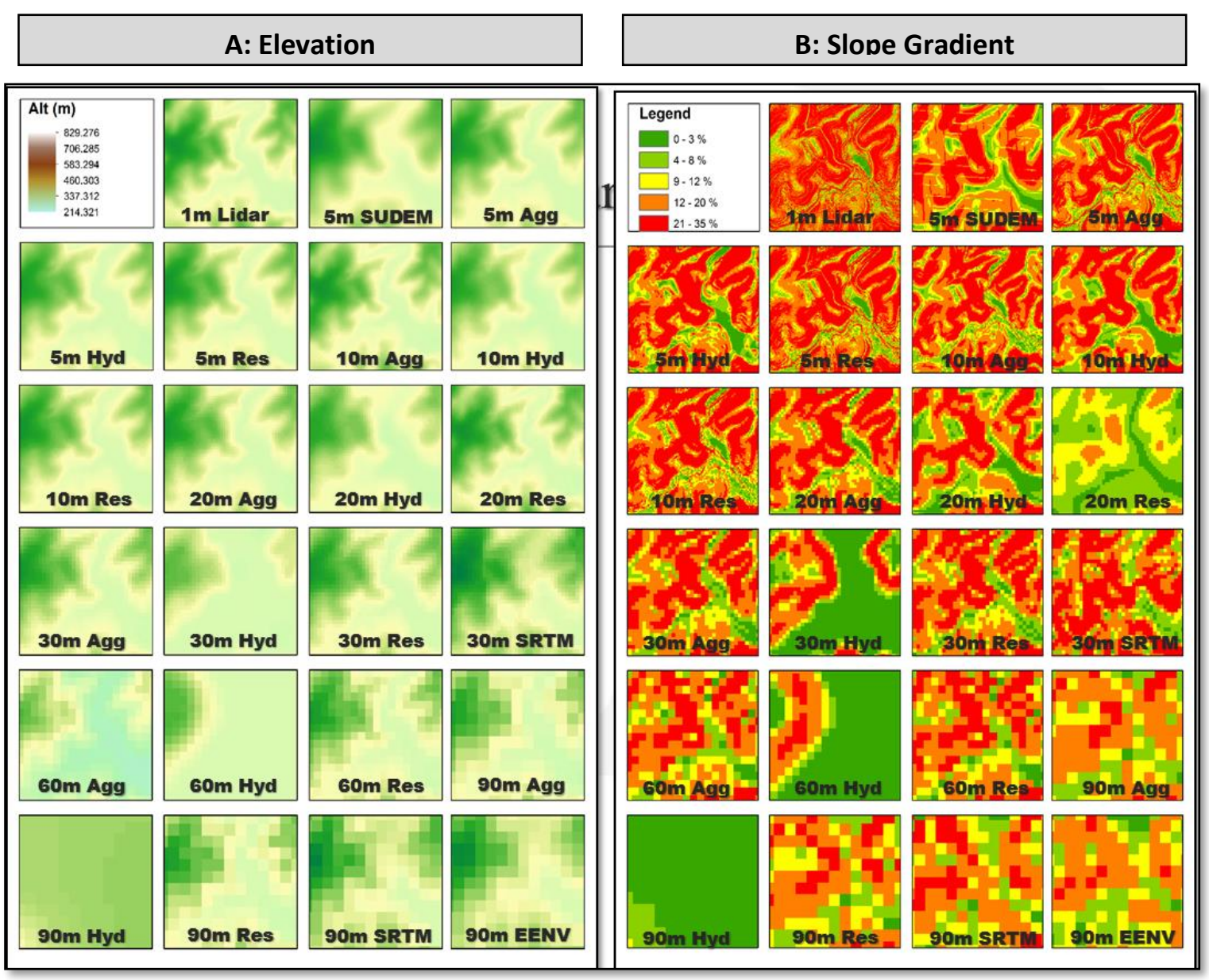

Figure 2: (a) Elevation surface product comparison between generalisation approaches and pixel resolution. (b) Slope comparison map showing variation in slope surfaces between LiDAR and non-LiDAR surfaces and pixel resolutions. 

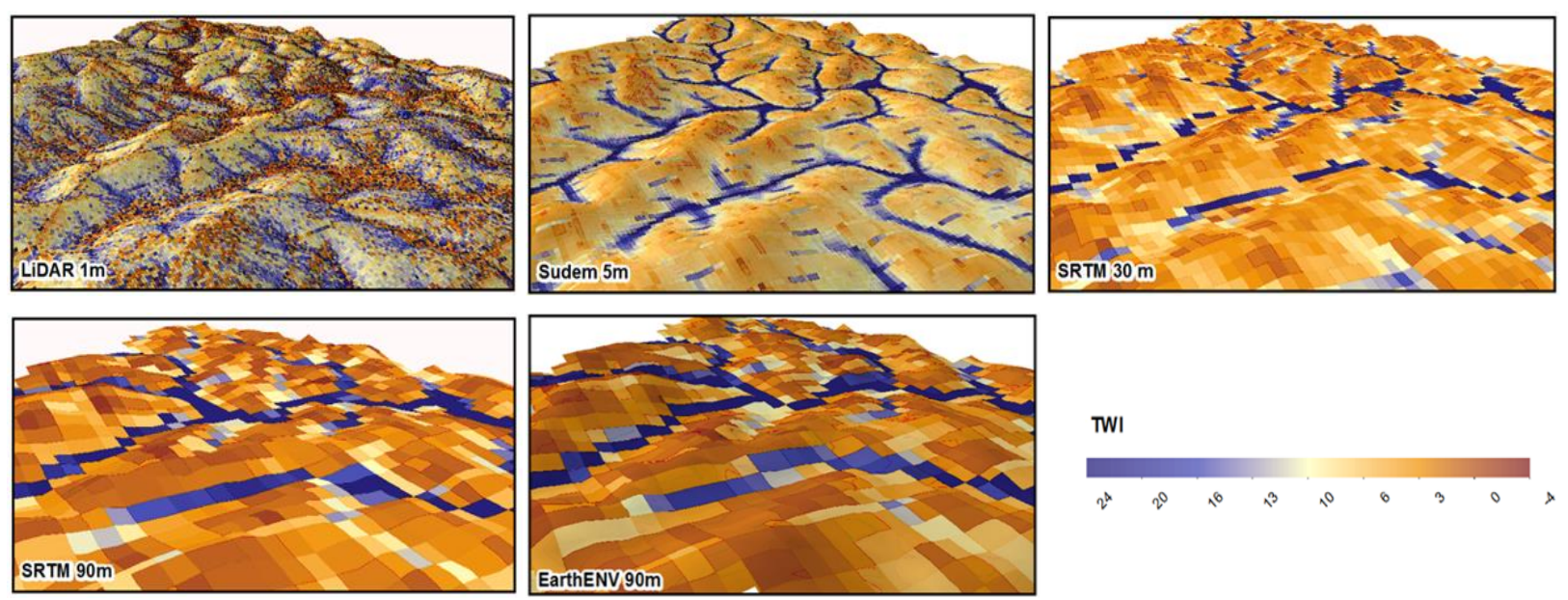

Figure 3: Maps showing the variation in TWI between the LiDAR and Non-LiDAR surface products.

However, the lower variability associated with the decreased resolution does not imply a better slope product. The $M A D$ for the same products in fact show a reverse trend of decreasing accuracy with decreased resolution with the $90 \mathrm{~m}$ products clearly showing errors in slope percentage by factors of 4 when compared to the higher resolution products such as the $5 \& 10 \mathrm{~m}$ products. Lindsay and Creed (2005) were able to show that depression removal significantly altered the spatial and statistical distributions of derived terrain attributes, including inter alia, slope gradient. As would then be expected, of the three generalisation approaches, the $H C D 90 \mathrm{~m}$ approach displayed the highest slope deviation of approximately $22 \%$ with the lowest deviation attributed to the $5 \mathrm{~m} N N R$ approach showing a $6 \%$ slope deviation from the $1 \mathrm{~m}$ LiDAR surface. Of the NLD products, the SUDEM and SRTM 30m MAD were highly correlated at approximately $11 \%$, with $M A D$ increasing between $13-$ $15 \%$ with a coarsening in spatial resolution to $90 \mathrm{~m}$ in the SRTM and EarthEnv slope products respectively.

Surprisingly, all the predicted slope values, regardless of pixel size or sensor platform, on average exhibited a positive bias. Although this may have been expected for the $H C D$ slope products given the topographical elimination of depression artefacts or sinks across the study site (Wechsler, 2006), we did not expect the results to uniformly over predict across all generalisation approaches. However, the high correlation and low variability between the DEM surfaces combined with the undulating terrain of the study site may offer some perspective on the obtained result. Wechsler (2006) showed that by sink filling, the elevation of cells where sinks were found increased resulting in a larger positive bias for elevation. The increased elevation consequently lead to increased slope estimators in these areas, resulting in positive bias for slope. Furthermore, the study highlighted the higher predominance of depressions in flat areas than in high-relief landscape.

Still, (Wechsler and Kroll, 2006) found similar trends of slope bias when comparing slope values to upslope contributing area estimators and further reported a $M A D$ of $8 \%$ across different slope estimations, concluding that the slope values were not significantly different from each other or the true surface slope. The $H C D$ approach clearly shows lower slope detail with pixel coarsening from 30 to $90 \mathrm{~m}$. In contrast, the $M A$ and $N N R$ products, with the exception of the $20 \mathrm{~m} N N R$ slope, appear 
to capture the main terrain features of the true surface slope up to a $60 \mathrm{~m}$ pixel resolution. In Fact, when compared to the $1 \mathrm{~m}$ LiDAR surface, it's clear that the $90 \mathrm{~m}$ slope products just do not capture the necessary slope gradient trends in the landscape. What is surprising is that the 5m SUDEM slope product, which offers the highest resolution of the NLD products, was shown to be statistically different from the true surface. The results from Table 3 highlight that the SUDEM exhibits not only a high MAD but also SD from the true surface. Moreover, the poor performance of the SUDEM may be as a result of spurious issues related to the processing of the base contour and spot height data which include banding and wave effects (Van Niekerk, 2012) with issues such as banding and striping (Figure 2b) clearly affecting the accuracy of the slope prediction.

\subsubsection{Topographic Wetness Index}

Topographic wetness index (TWI), a second order derivative of DEMs, can be computed as $\ln (a / \tan \beta)$ where $\boldsymbol{a}$ considers the specific upslope catchment drainage area through a certain point per unit slope gradient $(\tan \boldsymbol{\beta})$ (Sørensen, Zinko, and Seibert, 2006). Larger upslope drainage areas and shallower slopes will produce larger $T W I$ values, and are expected to have relatively higher water availability than locations with a small upslope and steep slopes which would receive a low index indicating high trends of surface runoff (Quinn, Beven, Chevallier, and Planchon, 1991). Thus TWI has become a common and widely used indicator for the spatial distribution of relative rather than actual moisture conditions within the landscape. Mean TWI and MAD values were concluded to be a suitable descriptors for comparing soil moisture results between various TWI products (Buchanan et al., 2014). The results clearly show that the Mean TWI values for the LiDAR derived as well as NLD products were able to approximate the true surface moisture accumulation fairly accurately with a TWI Mean value range of 4.46 from a pixel resolution of 5 to $90 \mathrm{~m}$.

The Mean TWI values, although in-line with other studies across similar landscapes (Tagil and Jenness, 2008), are not very high and generally indicate that that the area is well-drained (well drained $<7.7$ < poorly drained) (Giasson et al., 2006). This may be directly related to the fact that the FSD survey sites were limited to locations that were suitable for afforestation, thereby intentionally avoiding lower lying, wetter areas such as riparian zones or catchment drainage zones which are typically characterized by zones of hydrological accumulation and high TWI values. The TWI results for the $H C D$ products have performed exceptionally well with the $5 \mathrm{~m}$ and even $10 \mathrm{~m}$ products having amongst the lowest $S D$ and $M A D$ values when compared to the $N N R$ and $M A$ methods. This indicates that while the $H C D$ products intentionally eliminate surface artefacts such as sinks or depressions they do not necessarily eliminate all zones of water accumulation or flow direction for that matter. In fact, the $H C D$ surfaces are the best suited for identifying hydrological flow paths within the landscape. Given though that $T W I$ is highly dependent on slope gradient, and that the $H C D$ slope surfaces did not perform particularly well across the various pixel resolutions the authors did not expect the TWI to be so well represented. However Wilson, (2012) was able to show that DEM errors propagated strongly to slope but only moderately for TWI although the coefficient of variation for TWI varied more spatially than that of slope. Interestingly, his results show that the TWI values were less sensitive than slope to the input DEM. However note that as the resolution increases so too does the $S D$ for each TWI estimation suggesting that we can be less certain of the TWI at coarser resolutions. There is a clear pattern of decreased TWI prediction accuracy as pixel resolution decreased between the LD 
and NLD products. This has been shown to be expected given that TWI relies on the prediction of upslope area and the estimation of upslope area in turn is dependent on pixel resolution with increases in upslope area prediction error resulting in decreases in slope and TWI values (Sørensen et al., 2006). Thomas et al., (2017) point out that coarser DEM resolutions are more likely to produce narrower slope distributions and lower mean slope gradients, due to the loss of topographic detail resulting from surface smoothing, with lower gradients on steeper slopes and higher gradients on shallower slopes (Chang and Tsai, 1991; Thompson et al., 2001). Furthermore, larger Mean TWI values are also expected, as a result of less irregular flow paths and larger minimum areal units, with larger values in upper landscape positions and lower values in lower landscape positions (Thompson et al., 2001; Wu and Huang, 2008). These studies concluded that larger Mean TWI values were expected from coarser resolution DEMs, primarily due to the influence of catchment area distributions rather than slope (Gillin et al., 2015; Sørensen and Seibert, 2007).

Kuo et al., (1999) however suggest that high resolution DEM data may necessarily not be appropriate for TWI mapping either. Studies that evaluated groundwater flow directions typically were generally better represented by landscape topography rather than small-scale surface variations, and therefore smoother topographic surfaces represented in coarser resolutions were better suited to represent nearsurface flow pathways and water table positions (Gillin et al., 2015). This is perhaps best expressed by the results of the TWI representation between the $1 \mathrm{~m}$ LD and NLD products in Figure 3. It is clear that the high-resolution $1 \mathrm{~m}$ LiDAR TWI surface(s) provides far too much detail and redundancy in representing surface flow and zones of accumulation across the landscape. The 5m SUDEM provides perhaps the best general representation of flow diversion while the $90 \mathrm{~m}$ products still adequately represent the large accumulation zones of saturation in the landscape they are unable to detect smaller areas of upslope accumulation. The optimal DEM resolution for deriving TWI depends on the hydrological processes being modelled as well as the scale of the topographic features controlling them (Quinn et al., 1991) and user considerations need to focus on achieving a balance between appropriate levels of topographic accuracy, data processing and storage requirements combined with the need for interpretable outputs (Liu, 2008; MacMillan, Martin, Earle and McNabb, 2003; Hengl, 2006).

\section{Conclusion}

This study has shown that sensor selection and by default DEM resolution does not always determine the utility of the application and that careful consideration must be given to the generalisation approaches used in representing the scale-dependent terrain processes to be modelled. Whilst similar studies have evaluated the influence and applicability of fine and coarse resolution DEMs on terrain analyses, few studies have been conducted under local conditions. This study therefore endeavoured to demonstrate the importance of utilising DEM surfaces that are "fit-forpurpose" for describing the scale-dependent topographic relationships relevant to soil-landscape modelling for an area located along KZNs south coast region. While these results may explain the modelled geomorphological conditions within the southern coastal region of KZN, there is no reason to suggest that these results are limited to this region and should therefore be interpreted as being representative as the expected terrain or hydrological response unit for the entire moist coastal region of KZN. The key findings of this study can be summarised as follows: 
1) For features such as TWI, the $1 \mathrm{~m}$ LiDAR provides an extremely high level of detail, perhaps more than is necessary for most pedometric applications with possible limitations related to data redundancy processing time and scale-related issues of modelling soil-landscape relationships. The results further show that as the landscape exhibits more uniformity in morphology, the need for high resolution data becomes negligible and freely available data such as SUDEM, SRTM and EarthENV are able to account for the necessary variation in terrain properties such as elevation, slope and even TWI. The scale-interpolation dichotomy inherently influence the accurate detection of certain terrain features across the site with optimal results obtained where the neighbourhood size and pixel resolution were commensurate with the rate and extent of topographic variability within the landscape.

2) The results show that the nearest neighbour resampling and mean cell aggregation methods were the most accurate (compared to the true surface model) and precise (repeatable stable estimates) in their surface generalisations, able to retain the terrain properties across most tested resolutions. This study has also highlighted some major limitations concerning the retrieval of terrain properties such as elevation and slope from hydrologically corrected DEM surfaces. In particular, HCD derived surface parameters were not found to be reliable of the true surface estimates across a range of pixel resolutions. The study therefore cautions against the use of using hydrologically corrected DEM surfaces for the extraction and analysis of topographic parameters not related to hydrological applications.

3) While spatial resolution across sensor platform may influence the level of detail between DEMs, the magnitude of variation in DEM error is not commensurate with the magnitude of error observed in their derived surface parameters i.e. small deviations between DEM surfaces may translate into significant errors in slope and/or TWI as our results have shown. Our analyses demonstrate the need to not only quantify the scale dependency of terrain features within an area but also take cognisance of where in the landscape these features can be accurately represented for deriving terrain attributes. For instance, terrain parameters such as slope and TWI generally exhibited strong dependencies on elevation and spatial resolution with regards to statistical similarity to the true surface with lower accuracies observed at higher altitudes and coarser resolution surfaces. Given that many disciplines rely on the accurate representation and extraction of topographic variables for a variety of studies, the benefit of our study is that for applications of DSM in particular, the analyses of soil-landscape relationships in the southern coastal region of KZN have been better defined. Moreover, the generalisation approaches and data source combination for optimal description of surface properties has been explicitly described. Finding the right combination of when to upscale surface data, what DEMS to use and what spatial scale operate at to ensure that surface integrity is most optimal is largely still be context specific. However this study demonstrates a robust framework to interpret optimal sensor choice and spatial scale for understanding the geomorphological processes in the landscape for the southern-coastal area of KZN. 


\section{References}

1 Aguilar, F.J., Agüera, F., Aguilar, M.A., Carvajal, F., 2005, "Effects of Terrain Morphology, Sampling Density, and Interpolation Methods on Grid DEM Accuracy" Photogrammetric. Engineering \& Remote Sensing 71, 805-816.

2 Barber, C.P., Shortridge, A., 2005, "Lidar Elevation Data for Surface Hydrologic Modeling: Resolution and Representation Issues" Cartography \& Geographic. Information Science 32, 401-410.

3 Bishop, M.P., James, L.A., Shroder, J.F., Walsh, S.J., 2012, "Geospatial technologies and digital geomorphological mapping: Concepts, issues and research" Geomorphology 137, 5-26.

4 Buchanan, B.P., Fleming, M., Schneider, R.L., Richards, B.K., Archibald, J., Qiu, Z., Walter, M.T., 2014, "Evaluating topographic wetness indices across central New York agricultural landscapes" Hydrology \& Earth System Sciences 18, 3279-3299.

5 Cavazzi, S., Corstanje, R., Mayr, T., Hannam, J., Fealy, R., 2013, “Are fine resolution digital elevation models always the best choice in digital soil mapping?" Geoderma 195, 111-121.

6 CGIAR-CSI, 2011, Date accessed: 24 October 2016, from http://srtm.csi.cgiar.org.

7 Chang, K., and Tsai, B., 1991, "The effect of DEM resolution on slope and aspect mapping" Cartography and Geographic Information Systems 18, 69-77.

8 Chen, C., and Yue, T., 2010, "A method of DEM construction and related error analysis" Computer Geoscience 36, 717-725.

9 Conrad, O., Bechtel, B., Bock, M., Dietrich, H., Fischer, E., Gerlitz, L., Wehberg, J., Wichmann, V., and Boehner, J., 2015, "System for Automated Geoscientific Analyses (SAGA) v. 2.1.4" Geoscience Model Development 8, 1991-2007.

10 Desmet, P.J.J., 1997, "Effects of interpolation errors on the analysis of DEM" Earth Surface Processes and Landforms 22, 563-580.

11 Drăguţ, L., Minár, J., Csillik, O., Evans, I.S., 2013, "Land-surface segmentation to delineate elementary forms from Digital Elevation Models" Geomophometry 2013 2-5.

12 ERASMUS, D., 1998, "Forest Industry Soils Database (FSD) Co-operative. Soil Survey Standards for Consultants. Version 1.3" Pietermaritzburg.

13 ESRI, 2015, ArcGIS Desktop: Release 10.3, computer software, Environmental Systems Research Institute, Redlands, CA.

14 Farr, T.G., Kobrick, M., 2001, "The shuttle radar topography mission" American Geophysics Union 81, 583-585.

15 Farr, T.G., Rosen, P.A., Caro, E., Crippen, R., Duren, R., Hensley, S., Kobrick, M., Paller, M., Rodriguez, E., Roth, L., Seal, D., Shaffer, S., Shimada, J., Umland, J., Werner, M., Oskin, M., Burbank, D., Alsdorf, D., 2007, "The shuttle topography mission" Reviews of Geophysics 45 (2).

16 Florinsky, I.V., 2011, "Digital terrain analysis in soil science and geology" Elsevier Academic Press, Amsterdam, p. 379.

17 Gesch, D., Oimoen, M., Zhang, Z., Danielson, J., Meyer, D., 2011, "Validation of the ASTER Global Digital Elevation Model (GDEM) Version 2 over the Conterminous United States" USGS Report, USA.

18 Giasson, E., Clarke, R.T., Vasconcellos, A., Junior, I., Henrique, G., Tornquist, C.G., 2006, "Digital soil mapping using multiple logistic regression on terrain parameters in southern Brazil" Science \& Agriculture 63, 262-268.

19 Gillin, C.P., Bailey, S.W., McGuire, K.J., Prisley, S.P., 2015, "Evaluation of Lidar-derived DEMs through Terrain Analysis and Field Comparison" Photogrammetric Engineering \& Remote Sensing 81, 387-396.

20 Gonga-Saholiariliva, N., Gunnell, Y., Petit, C., Mering, C., 2011, "Techniques for quantifying the accuracy of gridded elevation models and for mapping uncertainty in digital terrain analysis" Progress in Physical Geography 35, 739-764.

21 Grohmann, C.H., Sawakuchi, A.O., 2013, "Influence of cell size on volume calculation using digital terrain models: A case of coastal dune fields" Geomorphology 180, 130-136.

22 Goulden, T., Hopkinson, C., Jamieson, R., Sterling, S., 2016, "Sensitivity of DEM, slope, aspect and watershed attributes to LiDAR measurement uncertainty" Remote Sensing of Environment 179, 23-35.

23 Guo, Q., Li, W., Yu, H., Alvarez, O., 2010, "Effects of topographic variability and Lidar sampling density on several DEM interpolation methods" Photogrammetric Engineering \& Remote Sensing 76, 701-712. 
24 Hays, W. L., 1988, Statistics (4th ed.), CBS College Publishing, New York.

25 Hengl, T., 2006, "Finding the right pixel size" Computers \& Geoscience 32, 1283-1298.

26 Hook, P.B., Burke, I.C., 2000, "Biogeochemistry in a shortgrass landscape: Control by topography, soil texture, and microclimate" Ecology 81, 2686-2703.

27 Hodgson, M.E., Jensen, J., Raber, G., Tullis, J., Davis, B. a, Thompson, G., Schuckman, K., 2005, “An Evaluation of Lidar-derived Elevation and Terrain Slope in Leaf-off Conditions" Photogrammetric Engineering \& Remote Sensing 71, 817-823

28 Jarihani, A.A., Callow, J.N., McVicar, T.R., Van Niel, T.G., Larsen, J.R., 2015, "Satellite-derived Digital Elevation Model (DEM) selection, preparation and correction for hydrodynamic modelling in large, lowgradient and data-sparse catchments" Journal of Hydrology 524, 489-506.

29 Krause, P., Boyle, D.P., 2005, "Advances in Geosciences Comparison of different efficiency criteria for hydrological model assessment "Advances in Geoscience 5, 89-97.

30 Kuo, W.L., Steenhuis, T.S., McCulloch, C.E., Mohler, C.L., Weinstein, D.A., DeGloria, S.D., Swaney, D.P., 1999, "Effect of grid size on runoff and soil moisture for a variable-source-area hydrology model" Water Resource Research 35, 3419-3428.

31 Lindsay, J.B., Creed, I.F., 2005, "Removal of artifact depressions from digital elevation models: towards a minimum impact approach" Hydrological. Processes, 19, 3113-3126.

32 Liu, X., 2008, "Airborne LiDAR for DEM generation: some critical issues” Progress in Physical Geography 32, 31-49.

33 MacMilland, R.A., Shary, P.A., 2009, "Landforms and landform elements in geo- morphometry" In: Hengl, T., Reuter, H.I. (Eds.), Geomorphometry: Concepts, Software, Applications. Developments in Soil Science 33, 227-254.

34 MacMillan, R.A., Martin, T.C., Earle, T.J., McNabb, D.H., 2003, "Automated analysis and classification of landforms using high-resolution digital elevation data: applications and issues" Canadian Journal of Remote Sensing 29, 592-606.

35 Mashimbye, Z.E., De Clercq, W.P., Van Niekerk, A., 2014, "An evaluation of digital elevation models (DEMs) for delineating land components" Geoderma 213, 312-319.

36 Maynard, J.J., Johnson, M.G., 2014, "Scale-dependency of LiDAR derived terrain attributes in quantitative soil-landscape modeling: Effects of grid resolution vs. neighbourhood extent" Geoderma 230, 29-40.

37 Nash, J.E., and Sutcliffe, J.V.; 1970, "River flow forecasting through conceptual models" Journal of Hydrology 10, $282-290$.

38 Nelson, A., Reuter, H.I., Gessler, P., 2009, "Dem Production methods and sources” Developments in Soil Science 33, 65-85.

39 Prasannakumar, V., Shiny, R., Geetha, N., Vijith, H., 2011, "Applicability of SRTM data for landform characterisation and geomorphometry: a comparison with contour-derived parameters" International Journal of Digital Earth 4,, 387-401.

40 Quinn, P., Beven, K., Chevallier, P., Planchon, O., 1991, "The prediction of hillslope flow paths for distributed hydrological modelling using digital terrain models" Hydrological Processes 5, 59-79.

41 Robinson, N., Regetz, J., Guralnick, R.P., 2014, "EarthEnv-DEM90: A nearly-global, void-free, multi-scale smoothed, 90m digital elevation model from fused ASTER and SRTM data" ISPRS Journal of Photogrammetry \& Remote Sensing 87, 57-67.

42 Rodriguez, E., Morris, C., Belz, J., 2005, "An assessment of the SRTM topographic products" Photogrammetric Engineering \& Remote Sensing 72, 249-260.

43 Shafique, M., van der Meijde, M., Kerle, N., van der Meer, F., 2011, "Impact of DEM source and resolution on topographic seismic amplification" International Journal of Applied Earth Observation and Geoinformation 13, 420-427.

44 Shi, X., Girod, L., Long, R., DeKett, R., Philippe, J., Burke, T., 2012, “A comparison of LiDAR-based DEMs and USGS-sourced DEMs in terrain analysis for knowledge-based digital soil mapping" Geoderma $170,217-226$.

45 Sørensen, R., Zinko, U., Seibert, J., 2006, “On the calculation of the topographic wetness index: evaluation of different methods based on field observations" Hydrology \&. Earth System Science 10, 101-112.

46 South African Sugarcane Research Institute (SASRI), 1999, "Identification and management of the soils of the South African Sugar Industry” Mount Edgcombe, South Africa. ISBN 1 -874903-1 7-4. 
47 Tagil, S., Jenness, J., 2008, "GIS-Based Automated Landform Classification and Topographic, Land cover and Geologic Attributes of Landforms around the Yazoren Polje, Turkey" Journal of Applied Sciences 8, 910-921.

48 Tate, N.J., Fisher, F., 2006, "Causes and consequences of error in digital elevation models" Progress in Physical Geography 30(4), 467-489.

49 Tesfa, T.K., Tarboton, D.G., Chandler, D.G., McNamara, J.P., 2009, "Modelling soil depth from topographic and land cover attributes" Water Resource Research, 45.

50 TerraTec AS. Computer Software, Date accessed 4 march 2016 from http://www.terratec.no/terrapos.html.

51 TerraScan. Computer Software, Date accessed 15 march 2016 from https://www.terrasolid.com.

52 Thomas, J., Joseph, S., Thrivikramji, K.P., Arunkumar, K.S., 2014, "Sensitivity of digital elevation models: The scenario from two tropical mountain river basins of the Western Ghats, India" Geoscience Frontiers $5,893-909$.

53 Thomas, I.A., Jordan, P., Shine, O., Fenton, O., Mellander, P.E., Dunlop, P., Murphy, P.N.C., 2017, "Defining optimal DEM resolutions and point densities for modelling hydrologically sensitive areas in agricultural catchments dominated by microtopography" International Journal of Applied Earth Observation and Geoinformation 54, 38-52.

54 Thompson, J.A., Bell, J.C., Butler, C.A., 2001, "Digital elevation model resolution: Effects on terrain attribute calculation and quantitative soil-landscape modeling" Geoderma 100, 67-89.

55 Van Niekerk, A., 2011, "Stellenbosch University Digital Elevation Model Product Description 2011 Edition" Centre for Geographical Analysis, Stellenbosch.

56 Van Niekerk, A., 2012, "Developing a High Resolution DEM of South Africa" Position IT, NovemberDecember, p. 55-60.

57 Van Niekerk, A., 2014, "Stellenbosch University Digital Elevation Model (SUDEM) version 13" Centre for Geographical Analysis, Stellenbosch.

58 Wechsler, S., 2006, "Uncertainties associated with digital elevation models for hydrologic applications: a review" Hydrology \&. Earth System Science Discussions 3, 2343-2384.

59 Wechsler, S.P., Kroll, C.N., 2006, "Quantifying DEM Uncertainty and its Effect on Topographic Parameters" Photogrammetric Engineering \& Remote Sensing 72, 1081-1090.

60 Wilson, J.P., 2012, "Digital terrain modeling” Geomorphology 137, 107-121.

61 Wise, S.M., 2000, “Assessing the quality for hydrological applications of digital elevation models derived from contours" Hydrological Processes 14 (11-12), 1909-1929.

$62 \mathrm{Wu}$, S., Li, J., Huang, G.H., 2008, “A study on DEM-derived primary topographic attributes for hydrologic applications: Sensitivity to elevation data resolution". Applied Geography 28, 210-223.

63 Zhang, J.X., Chang, K.T., Wu, J.Q., 2008, "Effects of DEM resolution and source on soil erosion modelling: a case study using the WEPP model" International Journal of Geographic Information Science 22, 925-942.

64 Zhou, Q., and Chen, Y., 2011. "Generalization of DEM for terrain analysis using a compound method". ISPRS Journal of Photogrammetry and Remote Sensing. 66, 38-45. 